\title{
Cardiovascular risk profiles of GnRH agonists and antagonists: real-world analysis from UK general practice
}

\author{
Patrick Davey ${ }^{1} \cdot$ Mike G. Kirby ${ }^{2}$
}

Received: 14 May 2020 / Accepted: 30 August 2020 / Published online: 26 September 2020

(c) The Author(s) 2020

\begin{abstract}
Purpose Androgen deprivation therapy (ADT) is the mainstay for the management of metastatic prostate cancer. Available pharmaceutical ADTs include gonadotropin-releasing hormone $(\mathrm{GnRH})$ agonists and antagonists. Here, real-world data are presented from the UK general practitioner Optimum Patient Care Research Database. The study investigated the hypothesis that $\mathrm{GnRH}$ antagonists have lower cardiac event rates than $\mathrm{GnRH}$ agonists.

Methods The incidence of cardiac events following initiation of GnRH antagonist or agonist therapy was investigated in a population-based cohort study conducted in UK primary care between 2010 and 2017.

Results Analysis of real-world data from the UK primary care setting showed that relative risk of experiencing cardiac events was significantly lower with degarelix, a GnRH antagonist, compared with GnRH agonists (risk ratio: 0.39 [95\% confidence interval 0.191, 0.799]; $p=0.01$ ). Patients that received degarelix as first-line treatment switched treatment more frequently (33.7\%), often to a GnRH agonist, than those who initiated treatment with a GnRH agonist (6.7-18.6\%).

Conclusion Screening for known or underlying vascular disease and identifying those at high risk of a cardiac event is important for risk mitigation in patients with prostate cancer receiving hormone therapy. The GnRH antagonist degarelix conferred a significantly lower risk of cardiac events than GnRH agonists. Prior to treatment, patients should be stratified based on level of cardiovascular (CV) risk, and appropriate lifestyle, and pharmacological interventions to mitigate $\mathrm{CV}$ risk should be recommended. CV risk factors and patient response to the intervention should be monitored at regular intervals.
\end{abstract}

Keywords Prostate cancer $\cdot$ Degarelix $\cdot$ GnRH agonist $\cdot$ GnRH antagonist $\cdot$ Cardiovascular

\section{Introduction}

Prostate cancer accounts for $\sim 20 \%$ of new cancer diagnoses in the USA and the EU, and is now the most commonly diagnosed cancer in England [1-3]. In the UK, there were around 47,700 new annual cases of prostate cancer from 2014 to $2016,49,029$ new annual cases in 2018, and incidence rates are estimated to rise by $12 \%$ between 2014 and 2035, to 233 cases per 100,000 men by 2035 [3]. In 2017, prostate cancer accounted for $14 \%$ of all cancer deaths in men in the UK [4]. Data released by Public Health England in 2018 indicate that prostate cancer is now the most diagnosed cancer

Patrick Davey

ppdavey@gmail.com

1 Northampton General Hospital, Cliftonville, Northampton NN1 5BD, UK

2 Trends in Urology \& Men's Health, Baldock, Herts SG7 5DX, UK in England, with almost 8000 more diagnoses of prostate cancer in 2018 than the previous year [5].

Androgen deprivation therapy (ADT) is the mainstay for the management of metastatic prostate cancer, and surgical castration has been superseded by non-surgical therapies, which are now the standard of care [5-7]. Available pharmaceutical ADTs include gonadotropin-releasing hormone $(\mathrm{GnRH})$ agonists, such as leuprolide, goserelin, triptorelin and buserelin acetate, and more recently, GnRH antagonists, such as degarelix and abarelix (approved in Germany and The Netherlands) [5, 8].

The incidence of cardiovascular disease (CVD) and prostate cancer increases with age, and CVD incidence and mortality are high in men with prostate cancer [9-11]. ADTs, and specifically GnRH agonists, have been associated with increased cardiovascular (CV) morbidity and mortality in observational studies, and men with pre-existing CVD are most at risk [12-17]. Data suggest that the risk for cardiac events might be lower with the GnRH antagonist degarelix, 
compared with GnRH agonists, particularly in patients with pre-existing CVD [18-21].

A recent analysis of real-world data from a UK general practitioner database comparing $\mathrm{CV}$ outcomes in patients treated with degarelix vs GnRH agonists is presented and discussed in this context.

\section{Methods}

\section{Study design}

A post hoc analysis of real-world data from the UK general practitioner database [Optimum Patient Care Research Database (OPCRD)] was conducted between 2010 and 2017. Over 700 general practices collaborate with OPC to contribute anonymized, patient-level diagnostic, clinical and prescribing information data to the OPCRD to enable scientific research to better understand chronic diseases and improve health outcomes [22]. To better understand if, in a real-world setting, GnRH antagonists have lower cardiac event rates than GnRH agonists, the database was used to compare cardiac event rates in patients with prostate cancer treated with degarelix vs GnRH agonists (leuprorelin, goserelin or triptorelin). Preliminary data were presented at the American Urological Association 2020 [23].

\section{Patients and baseline characteristics}

UK primary care patients $(n=9081)$ with prostate cancer, aged $\geq 40$ years, with no previous use of degarelix, leuprorelin, goserelin or triptorelin were included in analyses. Baseline characteristics (e.g. age, sex, body mass index, prostate-specific antigen [PSA] levels) were based on the data available closest to the initial prescription date. Information of pre-existing CVD and diabetes was based on data available up to the point of first ADT prescription. Pre-existing cardiac events were examined in a 'baseline period' of at least 1 year prior to the index prescription date (IPD, i.e. first prescription for degarelix or agonist).

\section{Study end points}

The aims of the study were to investigate the incidence of cardiac events following initiation of $\mathrm{GnRH}$ antagonist (degarelix) or GnRH agonist (leuprorelin, goserelin or triptorelin) as therapy in patients with prostate cancer.

Following initiation of degarelix or GnRH agonist, the risk of cardiac events [heart failure; myocardial infarction (MI); arrhythmia; ischaemic heart disease (IHD); and all events combined (any cardiac)] for degarelix relative to each GnRH agonist was assessed. Patients were followed from the IPD up until the date the patient either died, transferred out of general practice, switched to second-line treatment, the date of cardiac event, or until the end of data collection, whichever event came first.

The time to switch from first- to second-line treatment was also determined. The date of the first prescription of second-line treatment was defined as the switching date. When there was a gap of 2-6 months before the switching date, the start date of the gap was defined as the switching date.

\section{Statistical analysis}

Statistical analyses were conducted post hoc. Point estimation was calculated by maximum likelihood and the confidence intervals (CIs) were based on a Gaussian approximation on the logarithmic scale $[24,25] . p$ values (two-sided tests) were based on the same Gaussian assumptions as for the CIs. Differences between groups were assessed using Chi-square test, Fisher's exact test, Kruskal-Wallis or analysis of variance test (when appropriate). The differences were considered significant if the $p$ values were $<0.05$. No multiplicity adjustments were performed, in line with the reasoning in Sect. 2.4 of Committee for Proprietary Medicinal Products Points to Consider on Multiplicity Issues in Clinical Trials [26]. R version 3.6.3 (2020-02-29) (R Core Team 2018) was used for all analyses. All the tests were performed with SAS software, version 9.3 (SAS Institute, Cary, NC).

\section{Results}

\section{Study population}

In total, 101 patients received the $\mathrm{GnRH}$ antagonist degarelix, while the remainder of the cohort received a GnRH agonist (leuprorelin, $n=3289$; goserelin, $n=4366$; triptorelin, $n=1325$ ) as first-line treatment (Fig. 1). Baseline and disease characteristics of patients with prostate cancer receiving each treatment are presented in Table 1. Overall, baseline characteristics appear comparable; however, prostate cancer severity and cardiac history between patients receiving degarelix vs GnRH agonists differed (in the degarelix group, PSA levels were higher and more patients had cardiac disease at baseline).

\section{Cardiac events and other adverse events with degarelix vs $\mathrm{GnRH}$ agonists}

The relative risk of experiencing any cardiac event was lower with degarelix than all $\mathrm{GnRH}$ agonists (risk ratio [RR] 6.9\% vs $17.7 \%$; 0.39 [95\% CI 0.191, 0.799]; $p=0.01$ ). This was significant vs leuprorelin (RR 0.40 [95\% CI 0.197, 0.829]; $p=0.01$ ) and goserelin (RR 0.36 [95\% CI 0.175, $0.735] ; p=0.01$ ), and nearly but not quite reaching statistical 


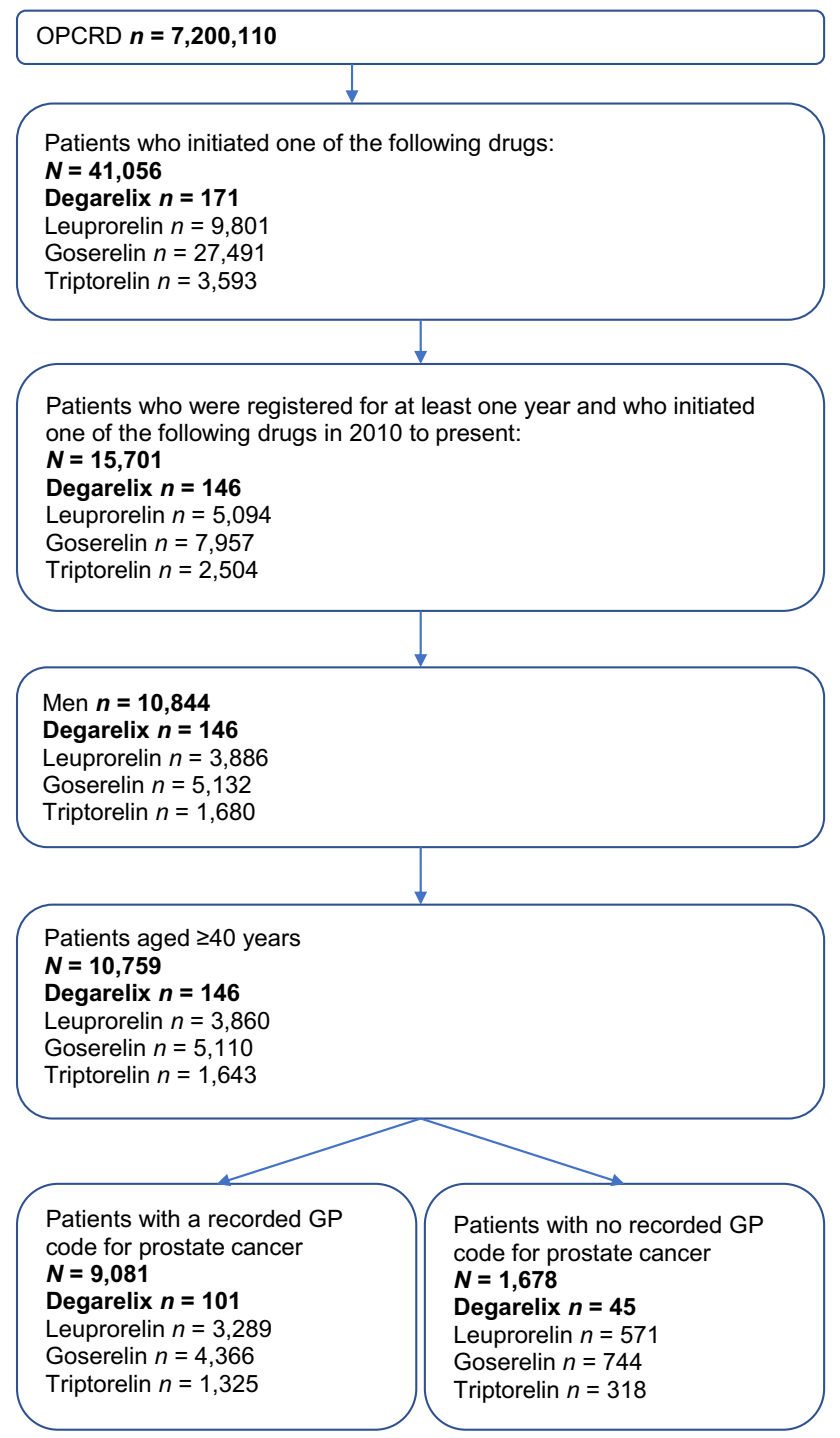

Fig. 1 Consort diagram

significance vs triptorelin (RR 0.50 [95\% CI 0.240, 1.027]; $p=0.06$ ). The effect of degarelix on cardiac event rates appeared to be largely driven by reductions in heart failure and arrythmia. By comparison, treatment effects on MI and IHD treatment were comparatively weak. The low number of patients in the degarelix group precluded any meaningful subgroup analyses (Table 2 and Fig. 2).

\section{Treatment switching from first-line ADT}

Patients who received degarelix as first-line ADT switched treatment more frequently than those that received a GnRH agonist (33.7\% vs $6.7-18.6 \%$; Table 3). The mean time to switch was 289.8 (SD 261.5) days with degarelix. Most degarelix-treated patients who switched treatment did so after 3 months $(67.6 \%)$, compared to within the first
3 months (32.4\%) of first-line ADT, and most patients switched to leuprorelin (41.2\%) or triptorelin (47.1\%).

\section{Discussion}

ADT lowers testosterone levels, which prevents androgen receptor signalling; however, GnRH agonists and antagonists suppress testosterone levels through different mechanisms, which may confer different CV risk as measured by event rates for patients with prostate cancer who receive ADT. GnRH agonists stimulate luteinizing hormone (LH) and follicle-stimulating hormone (FSH) release; this leads to reduced LH and FSH levels by receptor desensitization, resulting in suppressed testosterone secretion from the testicles [27-29]. In contrast, GnRH antagonists such as degarelix bind directly to GnRH receptors, leading to rapid suppression of LH and FSH and immediate decrease in testosterone secretion from the testicles, without an initial testosterone surge [30-32]. GnRH antagonists suppress FSH levels to a greater extent than GnRH agonists [33] and their differential effects on FSH levels might explain the differences in $\mathrm{CV}$ risk, development of atherosclerotic plaque formation, metabolic syndrome, and insulin resistance [34].

Treatment with GnRH agonists has been associated with increased CV morbidity and mortality [12, 13, 17, 35, 36]. The explanation of the differential CV risk between GnRH antagonists and agonists centres on $\mathrm{T}$ lymphocyte activation and destabilization of atherosclerotic plaques [37]. The GnRH receptor is expressed on pro-inflammatory $\mathrm{T}$ lymphocytes $[38,39]$ and upon activation an inflammatory cascade stimulates $\mathrm{T}$ cell proliferation, cytokine production, and macrophage activity leading to increased risk of atherosclerotic plaque rupture [20,37], disruption of atheromatous plaques, and fatal coronary thrombi [40]. Unlike GnRH agonists, GnRH antagonists lack the ability to activate T lymphocytes, thus maintaining plaque stability [37].

Preclinical studies showed that treatment with leuprolide, but not with degarelix, induced atherosclerotic plaque instability and that degarelix was associated with reduced atherosclerosis, decreased adiposity, and reduced characteristics of metabolic syndrome, compared with leuprolide [41].

In the current study, real-world data from UK primary care settings was used to investigate whether the risk of cardiac events may be lower in patients receiving degarelix compared with GnRH agonists. The study found that the relative risk of experiencing any cardiac event was lower with degarelix than all GnRH agonists $(p=0.01)$. Differences in the RR were statistically significant for degarelix compared with leuprorelin and goserelin (both $p=0.01$ ), but not for triptorelin $(p>0.05)$. The effect of degarelix on cardiac events appeared to be largely driven by reductions in heart failure and arrythmia. It should be noted that the number of 
Table 1 Baseline characteristics of prostate cancer patients prescribed degarelix, leuprorelin, goserelin, or triptorelin in a UK population-based cohort study $(n=9081)$

\begin{tabular}{|c|c|c|c|c|}
\hline Baseline characteristics $^{\mathrm{a}}$ & Degarelix users $n=101$ & Leuprorelin users $n=3289$ & Goserelin users $n=4366$ & Triptorelin users $n=1325$ \\
\hline Age, year & $n=100$ & $n=3276$ & $n=4366$ & $n=1325$ \\
\hline Mean (SD) & $74.8(9.0)$ & $75.9(8.6)$ & $74.0(8.5)$ & $75.3(8.3)$ \\
\hline $\mathrm{BMI}, \mathrm{kg} / \mathrm{m}^{2}, n(\%)$ & $n=93$ & $n=3091$ & $n=4012$ & $n=1207$ \\
\hline Mean (SD) & $26.9(5.0)$ & $27.4(4.9)$ & $27.5(4.5)$ & $27.3(4.5)$ \\
\hline Overweight: $25-30$ & $39(41.9)$ & $1364(44.1)$ & $1836(45.8)$ & $548(45.4)$ \\
\hline Obese: $>30$ & $21(22.6)$ & $745(24.1)$ & $993(24.7)$ & $295(24.4)$ \\
\hline Smoking status, $n(\%)$ & $n=97$ & $n=3162$ & $n=4103$ & $n=1258$ \\
\hline Current smoker & $9(9.3)$ & $278(8.8)$ & $458(11.2)$ & $146(11.6)$ \\
\hline Ex-smoker & $49(50.5)$ & $1464(46.3)$ & $1858(45.3)$ & $567(45.1)$ \\
\hline $\begin{array}{l}\text { PSA, } \mathrm{ng} / \mathrm{ml} \text {, closest to baseline, } n \\
(\%)\end{array}$ & $n=67$ & $n=2663$ & $n=3260$ & $n=1115$ \\
\hline Median (IQR) & $72.4(3.7-273.0)$ & $10.0(1.4-36.7)$ & $8.0(0.8-24.9)$ & $10.6(1.6-36.4)$ \\
\hline$<20$ & $27(40.3)$ & $1727(64.9)$ & $2312(70.9)$ & $694(62.2)$ \\
\hline$\geq 20$ & $40(59.7)$ & $936(35.1)$ & $948(29.1)$ & $421(37.8)$ \\
\hline Testosterone, $\mathrm{ng} / \mathrm{ml}$ & $n=5$ & $n=240$ & $n=324$ & $n=91$ \\
\hline Mean (SD) & $14.7(4.9)$ & $16.2(18.4)$ & $13.8(13.8)$ & $15.4(15.1)$ \\
\hline \multicolumn{5}{|l|}{$\begin{array}{l}\text { Comorbidity ever before/at baseline, } \\
n(\%)\end{array}$} \\
\hline Cardiovascular disease & $38(37.6)$ & $1075(32.7)$ & $1288(29.5)$ & $385(29.1)$ \\
\hline IHD & $22(21.8)$ & $639(19.4)$ & $822(18.8)$ & $213(16.1)$ \\
\hline $\mathrm{HF}$ & $4(4.0)$ & $168(5.1)$ & $154(3.5)$ & $53(4.0)$ \\
\hline MI & $15(14.8)$ & $324(9.8)$ & $420(9.6)$ & $88(6.6)$ \\
\hline Arrhythmia & $20(19.8)$ & $615(18.7)$ & $669(15.3)$ & $222(16.7)$ \\
\hline Chronic kidney disease & $13(12.9)$ & $524(15.9)$ & 598 (13.7) & $208(15.7)$ \\
\hline Hepatic impairment & $2(2.0)$ & 85 (2.6) & $121(2.8)$ & $39(2.9)$ \\
\hline Osteoporosis & $2(2.0)$ & $64(1.9)$ & $94(2.1)$ & $21(1.6)$ \\
\hline Urticaria & $2(2.0)$ & $88(2.7)$ & $152(3.5)$ & $30(2.3)$ \\
\hline \multicolumn{5}{|l|}{ UTIs } \\
\hline 1 & $9(8.9)$ & $169(5.1)$ & $229(5.3)$ & $65(4.9)$ \\
\hline 2 & $2(2.0)$ & $25(0.8)$ & $54(1.2)$ & \\
\hline$>2$ & $0(0)$ & $26(0.8)$ & $19(0.4)$ & $5(0.4)$ \\
\hline Diabetes mellitus & $19(18.8)$ & $532(16.2)$ & $704(16.1)$ & $213(16.1)$ \\
\hline \multicolumn{5}{|l|}{$\begin{array}{l}\text { Drug use } 6 \text { months before/at base- } \\
\text { line, } n(\%)\end{array}$} \\
\hline Antithrombotic treatment & $50(49.5)$ & $1297(39.4)$ & $1676(38.4)$ & $520(39.2)$ \\
\hline Anti-androgens & $10(9.9)$ & 1185 (36.0) & $1521(34.8)$ & $612(46.2)$ \\
\hline
\end{tabular}

$B M I$ body mass index, $H F$ heart failure, $I H D$ ischaemic heart disease, $I Q R$ interquartile range, $M I$ myocardial infarction, $P S A$ prostate-specific antigen, $S D$ standard deviation, UTI urinary tract infection

${ }^{a}$ Closest to baseline for: age, sex, BMI, smoking status, PSA, testosterone; ever before baseline: comorbidity

patients taking degarelix in the UK is low, with clinicians currently using GnRH agonists as first-line treatments. However, the preliminary results of this study support findings from several other studies that suggest $\mathrm{GnRH}$ antagonists are associated with a lower cardiac risk than agonists.

Most but not all real-world observational data suggest that treatment with GnRH antagonists is associated with fewer cardiovascular event rates than treatment with GnRH agonists [35]. Real-world observational data from 2382 patients with advanced prostate cancer from a German claims database showed no significant differences in the incidence of CVD or diabetes between GnRH agonists or antagonists overall, although there was a significant increase in hypertension in patients receiving a GnRH agonist (16.4\%) compared with those receiving a GnRH antagonist $6.9 \%$, $p=0.022$ ) [42]. Similarly, data from 35,118 ADT users identified from a French population-based claims reimbursement database demonstrated no significant association between 
Table 2 Cardiovascular events in patients with prostate cancer treated with degarelix, leuprorelin, goserelin or triptorelin

\section{Degarelix users $n=101 \quad$ Leuprorelin $n=3289 \quad$ Goserelin $n=4366 \quad$ Triptorelin $n=1325 \quad$ GnRH agonists}

(pooled) $n=8980$

\begin{tabular}{|c|c|c|c|c|c|}
\hline \multicolumn{6}{|c|}{ Patients with an incident cardio event after initiation of therapy } \\
\hline Any cardiac event, $n(\%)$ & $7(6.9)$ & $564(17.1)$ & $844(19.3)$ & $185(14.0)$ & $1593(17.7)$ \\
\hline Relative risk $(95 \% \mathrm{CI})^{\mathrm{a}}$ & - & $0.40(0.197,0.829)$ & $0.36(0.175,0.735)$ & $0.50(0.240,1.027)$ & $0.39(0.191,0.799)$ \\
\hline$p$ value & - & 0.0135 & 0.0051 & 0.0590 & 0.0101 \\
\hline $\mathrm{HF}, n(\%)$ & $1(1.0)$ & $140(4.3)$ & $196(4.5)$ & $52(3.9)$ & $388(4.3)$ \\
\hline Relative risk $(95 \% \mathrm{CI})^{\mathrm{a}}$ & - & $0.23(0.033,1.646)$ & $0.22(0.031,1.558)$ & $0.25(0.035,1.806)$ & $0.23(0.033,1.615)$ \\
\hline$p$ value & - & 0.1441 & 0.1297 & 0.1703 & 0.1392 \\
\hline MI, $n(\%)$ & $2(2.0)$ & $80(2.4)$ & $147(3.4)$ & $24(1.8)$ & $251(2.8)$ \\
\hline Relative risk $(95 \% \mathrm{CI})^{\mathrm{a}}$ & - & $0.81(0.203,3.266)$ & $0.59(0.148,2.341)$ & $1.09(0.262,4.560)$ & $0.71(0.179,2.809)$ \\
\hline$p$ value & - & 0.7717 & 0.4513 & 0.9026 & 0.6238 \\
\hline Arrhythmia, $n(\%)$ & $3(3.0)$ & $308(9.4)$ & $516(11.8)$ & $115(8.7)$ & $939(10.5)$ \\
\hline Relative risk $(95 \% \mathrm{CI})^{\mathrm{a}}$ & - & $0.32(0.104,0.972)$ & $0.25(0.082,0.768)$ & $0.34(0.111,1.058)$ & $0.28(0.093,0.867)$ \\
\hline$p$ value & - & 0.0444 & 0.0154 & 0.0625 & 0.0271 \\
\hline $\mathrm{IHD}, n(\%)$ & $5(4.9)$ & $264(8.0)$ & $377(8.6)$ & $63(4.7)$ & $704(7.8)$ \\
\hline Relative risk $(95 \% \mathrm{CI})^{\mathrm{a}}$ & - & $0.62(0.260,1.461)$ & $0.57(0.243,1.355)$ & $1.04(0.428,2.530)$ & $0.63(0.268,1.489)$ \\
\hline$p$ value & - & 0.2720 & 0.2048 & 0.9290 & 0.2934 \\
\hline \multicolumn{6}{|c|}{ Time from initiation therapy to the first cardio event } \\
\hline Mean, days (SD) & $244.9(220.1)$ & $542.9(572.0)$ & $613.7(618.5)$ & $605.3(502.3)$ & - \\
\hline Median, days (IQR) & $206.0(85.0-219.0)$ & $322.5(137.0-751.0)$ & $415.0(136.5-880.5)$ & $493.0(215.0-853.0)$ & - \\
\hline
\end{tabular}

$C I$ confidence interval, $C V$ cardiovascular, $G n R H$ gonadotropin-releasing hormone, $H F$ heart failure, $I H D$ ischaemic heart disease, $I Q R$ interquartile range, $M I$ myocardial infarction, $S D$ standard deviation

${ }^{a}$ Relative risk with degarelix vs leuprorelin, goserelin, triptorelin and pooled $\mathrm{GnRH}$ agonists

GnRH antagonists and CV risk [43]. Finally, a retrospective analysis from the Scottish Cancer Registry reported a $30 \%$ and 50\% increase in CVD risk with GnRH agonists and degarelix, respectively, compared with untreated patients. However, the authors state the association of higher CV risk with ADT compared with untreated patients was largely driven by $\mathrm{CV}$ events in GnRH agonist-treated patients [44].

In contrast and in line with the results from this study, an Italian real-world analysis showed the incidence of CV events was significantly higher in patients treated with GnRH agonists compared with antagonists (6.2 vs 8.8 per 100 person-year, $p=0.002$ ) [45]. Further, disproportionality analysis from the pharmacovigilance database, Vigibase, found that of 10,504 and 1606 adverse drug reactions reported for $\mathrm{GnRH}$ agonists and antagonists, respectively, the respective numbers of cardiac-related events were 805 (7.7\%) and $102(6.4 \%)$. The time from initiation of therapy to onset of adverse event was over 1 year (mean 541.9 days, SD 909.6) [36].

There is conflicting data from randomized trials concerning cardiovascular event rates in $\mathrm{GnRH}$ agonist vs antagonist therapy. However, most of these trials were not set up to determine cardiovascular outcomes. One trial that was specifically set up to look at cardiovascular outcomes in $(n=80)$ those with pre-existing cardiovascular disease, showed
GnRH antagonist treatment was associated with fewer major $\mathrm{CV}$ and cerebrovascular events than treatment with $\mathrm{GnRH}$ agonists. The absolute risk reduction for a major $\mathrm{CV}$ event (defined as either death, MI, cerebrovascular event, or percutaneous-angioplasty with coronary stent insertion) at 12 months using a GnRH antagonist was $18.1 \%$ (95\% CI $4.6-31.2, p=0.032$ ) [19]. Further, a post hoc analysis of six Phase 3 trials $(n=2328)$ reported a significantly lower 1 -year risk of cardiac events (arterial embolic and thrombotic events, haemorrhagic or ischaemic cerebrovascular conditions, MI, or other IHD) among men with pre-existing CVD initiating degarelix compared with GnRH agonist therapy. The absolute risk reduction during the first year was $8.2 \%$ and the number of patients needed to be treated to avoid one CV event or death was 12 [18].

The findings of the current study are also in line with a recent Phase 3 trial which investigated CV risk as a prespecified safety analysis in 622 patients with advanced prostate cancer who received a GnRH antagonist (relugolix) compared with 308 patients who received a GnRH agonist (leuprolide), and suggested reduced CV risks with GnRH antagonists compared with agonists [46]. Among all patients, the incidence of major adverse $\mathrm{CV}$ events (defined as non-fatal MI, non-fatal stroke, and death from any cause) was $2.9 \%$ (exact 95\% CI 1.7-4.5) in the relugolix group and 


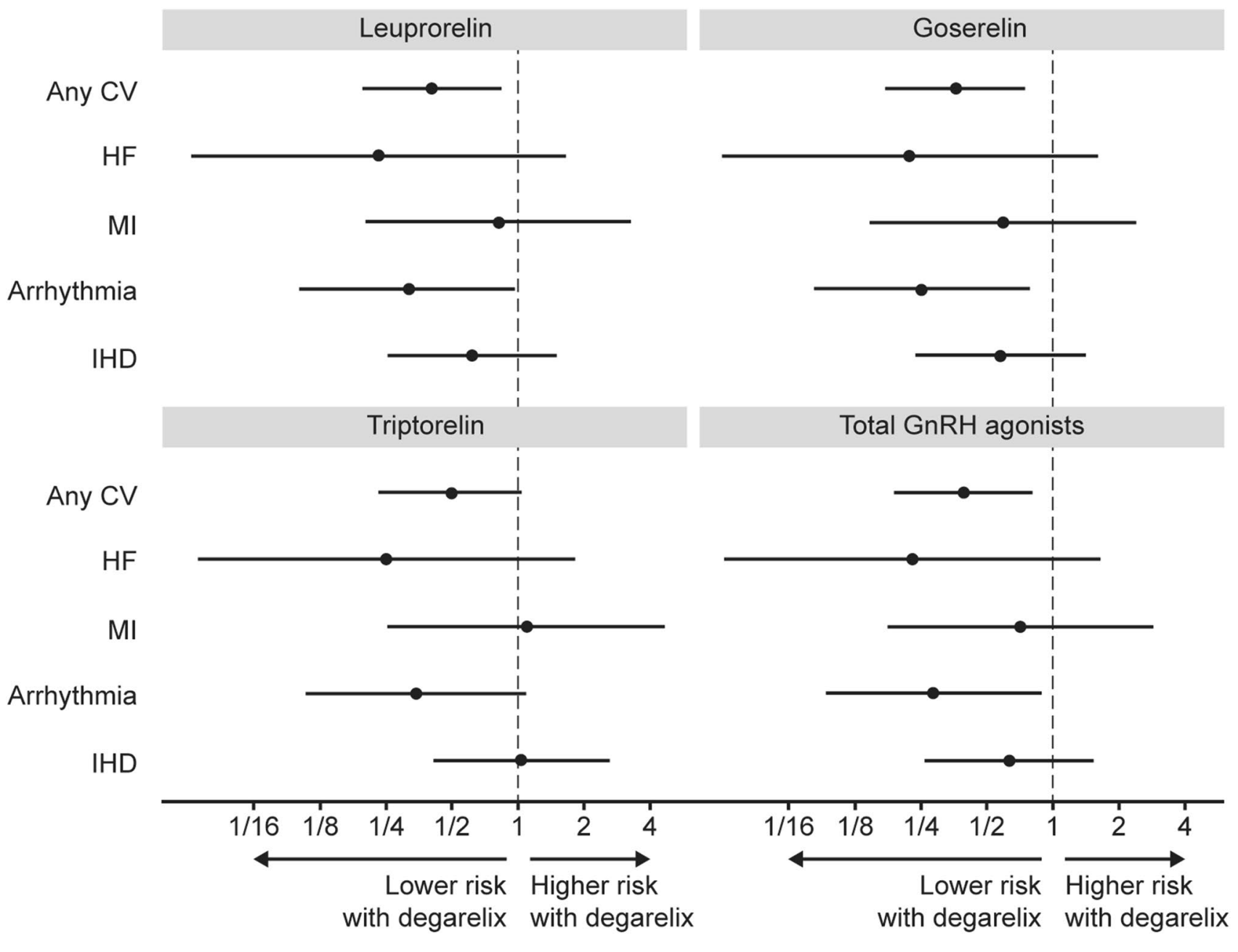

Relative risk

\section{Lines indicate the $95 \%$ confidence intervals for each estimate}

Fig. 2 Estimated relative risk of experiencing cardiovascular events in patients with prostate cancer treated with first-line degarelix $(n=101)$ vs leuprorelin $(n=3289)$, goserelin $(n=4366)$, triptorelin $(n=1325)$, and pooled $\mathrm{GnRH}$ agonists $(n=9081)$

Table 3 First switch to second-line treatment in patients with prostate cancer prescribed first-line degarelix, leuprorelin, goserelin or triptorelin

\begin{tabular}{llll}
\hline Parameter & Degarelix users $n=101$ & Leuprorelin $n=3289$ & Goserelin $n=4366$
\end{tabular}

Switched to second-line treatment

$\begin{array}{llll}n(\%) & 34(33.7) & 221(6.7) & 812(18.6)\end{array}$

Time to switch from initiation therapy to second-line treatment, days

\begin{tabular}{lllll} 
Mean (SD) & $289.8(261.5)$ & $453.6(538.4)$ & $559.1(542.2)$ & $354.2(448.1)$ \\
Median (IQR) & $234.0(53.0-448.0)$ & $280.0(84.0-587.0)$ & $378.0(121.0-810.0)$ & $167.0(84.0-453.0)$ \\
\hline
\end{tabular}

$I Q R$ interquartile range, $S D$ standard deviation

$6.2 \%$ (exact 95\% CI 3.8-9.5) in the leuprolide group (hazard ratio 0.46 ; 95\% CI 0.24-0.88). Kaplan-Meier estimates of the major $\mathrm{CV}$ event incidence rate were consistent with a $54 \%$ lower risk in patients who received relugolix vs leuprolide (hazard ratio 0.46 ; 95\% CI $0.24-0.88$ ). In a subgroup of patients with a reported medical history of $\mathrm{CV}$ events, the incidence of major adverse $\mathrm{CV}$ events was $3.6 \%$ in the relugolix group vs $17.8 \%$ in the leuprolide group.

In the current study, more patients who were treated with degarelix as first-line treatment switched treatment than those who received first-line treatment with a GnRH agonist. Most patients switched either within the first 3 months 
of first-line treatment or after 12 months, and most switched to leuprorelin or triptorelin. Therapeutic drug switching does occur and may be done for convenience, to reduce cost or to reduce side effects [47]. However, while there is some evidence of clinical benefit in switching a patient from a GnRH agonist to an antagonist [48] there is limited evidence for the opposite approach with no established protocols for switching between these different classes of drug [47]. Further, with real-world evidence studies showing mean time to $\mathrm{CV}$ event beyond 1-year [36], long-term treatment on an antagonist may be required to reduce $\mathrm{CV}$ risk.

In summary, the available data suggests that GnRH agonists increase $\mathrm{CV}$ events, and this effect appears to be greatest in patients with pre-existing CVD, and GnRH antagonists may be associated with lower rates of certain $\mathrm{CV}$ events vs GnRH agonists, particularly in patients with pre-existing CVD. The results in the present study support the hypothesis that the risk of cardiac events may be lower in patients receiving a GnRH antagonist such as degarelix, compared with GnRH agonists. However, there are several important limitations to consider.

\section{Study limitations}

All observational studies are vulnerable to bias and confounding, especially in terms of patient selection, differences in data capture and reporting. Indeed, an important limitation of the current study is that no steps were taken to minimize the risk of selection bias. Since some important differences in the baseline characteristics of patients were noted, including that more patients receiving degarelix had pre-existing CVD compared with patients receiving GnRH agonists, the current study results are vulnerable to confounding in terms of patient selection.

A further potential limitation is that the patients were all from a UK database, which could limit the generalizability of the findings to other regions. A major limitation was the small sample size of degarelix-treated patients, which prevented subgroup analysis of individual risk factors. The small sample size is common to other retrospective analyses of degarelix, with the low number of patients taking degarelix possibly due to clinicians favouring GnRH agonists as first-line treatments [42, 47]. Further, events of hypertension, stroke, and CV death were not included in the analysis. The higher $\mathrm{CV}$ risk associated with ADT was largely driven by cardiac events in $\mathrm{GnRH}$ agonist-treated patients.

Importantly, the statistical analyses were conducted post hoc and were not powered to determine statistical significance between therapies; in addition to the degarelix-treated patient group being small $(n=101)$, the stage of prostate cancer was unknown, PSA and testosterone levels were not available post-treatment, and data were from the OPCRD database; therefore, these findings may not be directly transferable to secondary care. Time from treatment initiation to first CV event was shorter with degarelix compared with $\mathrm{GnRH}$ agonists (244.9 days vs 542.9 for leuprorelin, 613.7 for goserelin and 605.3 days for triptorelin) which might reflect a greater cardiac event risk in these patients. A key limitation is that time on treatment was not collected as per the study protocol, and potential differences in exposure time between treatments could therefore not be corrected for. Further research is required on the association between degarelix and CV events; a randomized controlled trial administering degarelix or leuprorelin is currently ongoing [49].

\section{Conclusion}

Although the recent UK real-word study had several important limitations, the data showed that the relative risk of cardiac events was significantly lower with degarelix as first-line ADT (specifically heart failure and arrythmia) compared with GnRH agonists. While not definitive, the literature has previously shown that GnRH agonist treatment increases CVD and diabetes risk and that negative effects may be greatest in patients with pre-existing CVD. In contrast, it appears that GnRH antagonist therapy in this study and others is associated with lower rates of CVD than in those treated with GnRH agonists.

Given these findings, screening for known and undiagnosed metabolic and CV risk factors may be the key to risk mitigation in patients with prostate cancer receiving ADT. Appropriate therapy for prostate cancer, lifestyle, and other pharmacological interventions should be recommended, and $\mathrm{CV}$ risk factors should be monitored regularly.

Author contributions PD and MK conceptualized this review manuscript, provided critical feedback on each draft and approved the final draft for submission.

Funding Medical writing support, funded by Ferring Pharmaceuticals Ltd (UK), was provided by Hannah Fleetwood and Kate Booth, on behalf of Bioscript Science, Macclesfield, UK. Data acquisition and analysis (funded by Ferring Pharmaceuticals Ltd [UK]) was conducted through Open Vie by Prof David Price, Hilda de Jong and Dr Rupert Jones.

\section{Compliance with ethical standards}

Conflict of interest PD has recently received speaker fees from Bayer, Boehringer Ingelheim and Ferring Pharmaceuticals. In the past 36 months, MK has received funding for lecturing and conference attendance from Besins Healthcare, Astra Zeneca, Eli Lilly, Boehringer Ingelheim, Pfizer and Prostate Cancer UK.

Ethics approval The Optimum Patient Care Research Database (OPCRD) used for the analysis of new UK real-world data in this arti- 
cle is approved by Trent Multi Centre Research Ethics Committee for clinical research use.

Open Access This article is licensed under a Creative Commons Attribution 4.0 International License, which permits use, sharing, adaptation, distribution and reproduction in any medium or format, as long as you give appropriate credit to the original author(s) and the source, provide a link to the Creative Commons licence, and indicate if changes were made. The images or other third party material in this article are included in the article's Creative Commons licence, unless indicated otherwise in a credit line to the material. If material is not included in the article's Creative Commons licence and your intended use is not permitted by statutory regulation or exceeds the permitted use, you will need to obtain permission directly from the copyright holder. To view a copy of this licence, visit http://creativecommons.org/licenses/by/4.0/.

\section{References}

1. Siegel RL, Miller KD, Jemal A (2018) Cancer statistics. CA Cancer J Clin 68(1):7-30

2. Corcetti E (2015) Epidemiology of prostate cancer in Europe. https://ec.europa.eu/jrc/en/publication/epidemiology-prostatecancer-europe. Accessed 10 Aug 2020

3. Prostate Cancer UK Press Release (2020) Prostate cancer now most commonly diagnosed cancer in England. https:// prostatecanceruk.org/about-us/news-and-views/2020/1/prost ate-cancer-now-most-commonly-diagnosed-cancer-in-engla nd\#: :text=You\%2520are\%2520here\%3A-,Prostate\%2520cancer $\% 2520$ now $\% 2520$ most $\% 2520$ commonly $\% 2520$ diagnosed $\% 2520 \mathrm{c}$ ancer\%2520in $\% 2520$ England,most $\% 2520$ common $\% 2520$ cancer $\% 2520$ in\%2520England. Accessed 10 Aug 2020

4. Cancer Research UK (2020) Prostate cancer statistics. https:// www.cancerresearchuk.org/health-professional/cancer-statistics/ statistics-by-cancer-type/prostate-cancer. Accessed 10 Aug 2020

5. Cornford P, Bellmunt J, Bolla M et al (2017) EAU-ESTROSIOG guidelines on prostate cancer. Part II: Treatment of relapsing, metastatic, and castration-resistant prostate cancer. Eur Urol 71(4):630-642

6. Labrie F, Belanger A, Luu-The V et al (2005) Gonadotropinreleasing hormone agonists in the treatment of prostate cancer. Endocr Rev 26(3):361-379

7. Perlmutter MA, Lepor H (2007) Androgen deprivation therapy in the treatment of advanced prostate cancer. Rev Urol 9(Suppl 1):S3-8

8. Prostate Cancer UK (2016) Hormone therapy. https://prostateca nceruk.org/prostate-information/treatments/hormone-therapy. Accessed 26 Sep 2019

9. Studer UE, Whelan P, Albrecht W et al (2006) Immediate or deferred androgen deprivation for patients with prostate cancer not suitable for local treatment with curative intent: European Organisation for Research and Treatment of Cancer (EORTC) Trial 30891. J Clin Oncol 24(12):1868-1876

10. Calais da Silva FE, Bono AV, Whelan P et al (2009) Intermittent androgen deprivation for locally advanced and metastatic prostate cancer: results from a randomised phase 3 study of the South European Uroncological Group. Eur Urol 55(6):1269-1277

11. Driver JA, Djousse L, Logroscino G, Gaziano JM, Kurth T (2008) Incidence of cardiovascular disease and cancer in advanced age: prospective cohort study. BMJ 337:a2467

12. Bosco C, Bosnyak Z, Malmberg A, Adolfsson J, Keating NL, Van Hemelrijck M (2015) Quantifying observational evidence for risk of fatal and nonfatal cardiovascular disease following androgen deprivation therapy for prostate cancer: a meta-analysis. Eur Urol 68(3):386-396

13. Gandaglia G, Sun M, Popa I et al (2015) Cardiovascular mortality in patients with metastatic prostate cancer exposed to androgen deprivation therapy: a population-based study. Clin Genitourin Cancer 13(3):e123-130

14. Hedlund PO, Johansson R, Damber JE et al (2011) Significance of pretreatment cardiovascular morbidity as a risk factor during treatment with parenteral oestrogen or combined androgen deprivation of 915 patients with metastasized prostate cancer: evaluation of cardiovascular events in a randomized trial. Scand J Urol Nephrol 45(5):346-353

15. Keating NL, O'Malley A, Freedland SJ, Smith MR (2012) Diabetes and cardiovascular disease during androgen deprivation therapy: observational study of veterans with prostate cancer. J Natl Cancer Inst 104(19):1518-1523

16. Nanda A, Chen MH, Braccioforte MH, Moran BJ, D'Amico AV (2009) Hormonal therapy use for prostate cancer and mortality in men with coronary artery disease-induced congestive heart failure or myocardial infarction. JAMA 302(8):866-873

17. O'Farrell S, Garmo H, Holmberg L, Adolfsson J, Stattin P, Van Hemelrijck M (2015) Risk and timing of cardiovascular disease after androgen-deprivation therapy in men with prostate cancer. J Clin Oncol 33(11):1243-1251

18. Albertsen PC, Klotz L, Tombal B, Grady J, Olesen TK, Nilsson J (2014) Cardiovascular morbidity associated with gonadotropin releasing hormone agonists and an antagonist. Eur Urol 65(3):565-573

19. Margel D, Peer A, Ber Y et al (2019) Cardiovascular morbidity in a randomized trial comparing GnRH agonist and GnRH antagonist among patients with advanced prostate cancer and preexisting cardiovascular disease. J Urol 202(6):1199-1208

20. Greiman AK, Keane TE (2017) Approach to androgen deprivation in the prostate cancer patient with pre-existing cardiovascular disease. Curr Urol Rep 18(6):41

21. Sciarra A, Fasulo A, Ciardi A et al (2016) A meta-analysis and systematic review of randomized controlled trials with degarelix versus gonadotropin-releasing hormone agonists for advanced prostate cancer. Medicine (Baltimore) 95(27):e3845

22. Optimum Patient Care (OPC) UK. https://optimumpatientcare. org/who-we-are/our-story/. Accessed 5 Aug 2020

23. Davey P, Kirby M (2020) PD10-12 Cardiovascular risk with GnRH agonists and antagonists: real-world data from UK primary care. J Urol 203:e250-e251

24. Katz D, Baptista J, Azen SP, Pike MC (1978) Obtaining confidence intervals for the risk ratio in cohort studies. Biometrics 34(3):469-474

25. Woodward M (2005) Epidemiology: study design and data analysis, 2nd edn. Chapman \& Hall/CRC, Boca Raton

26. EMEA CPMP (2002) Points to consider on multiplicity issues in clinical trials. https://www.ema.europa.eu/en/documents/scien tific-guideline/points-consider-multiplicity-issues-clinical-trial s_en.pdf. Accessed 31 Mar 2020

27. van Poppel H, Nilsson S (2008) Testosterone surge: rationale for gonadotropin-releasing hormone blockers? Urology 71(6):1001-1006

28. Anderson J (2009) Degarelix: a novel gonadotropin-releasing hormone blocker for the treatment of prostate cancer. Future Oncol 5(4):433-443

29. van Poppel H, Klotz L (2012) Gonadotropin-releasing hormone: an update review of the antagonists versus agonists. Int J Urol 19(7):594-601

30. Cook T, Sheridan WP (2000) Development of GnRH antagonists for prostate cancer: new approaches to treatment. Oncologist $5(2): 162-168$ 
31. Huirne JA, Lambalk CB (2001) Gonadotropin-releasing-hormonereceptor antagonists. Lancet 358(9295):1793-1803

32. Boccon-Gibod L, Iversen P, Persson BE (2009) Degarelix 240/80 mg: a new treatment option for patients with advanced prostate cancer. Expert Rev Anticancer Ther 9(12):1737-1743

33. Klotz L, Boccon-Gibod L, Shore ND et al (2008) The efficacy and safety of degarelix: a 12-month, comparative, randomized, open-label, parallel-group phase III study in patients with prostate cancer. BJU Int 102(11):1531-1538

34. Crawford ED, Schally AV, Pinthus JH et al (2017) The potential role of follicle-stimulating hormone in the cardiovascular, metabolic, skeletal, and cognitive effects associated with androgen deprivation therapy. Urol Oncol 35(5):183-191

35. Nguyen PL, Je Y, Schutz FA et al (2011) Association of androgen deprivation therapy with cardiovascular death in patients with prostate cancer: a meta-analysis of randomized trials. JAMA 306(21):2359-2366

36. Cone EB, Marchese M, Reese SW et al (2020) Lower odds of cardiac events for gonadotrophin-releasing hormone antagonists versus agonists. BJU Int 126(1):9-10

37. Rosario DJ, Davey P, Green J et al (2016) The role of gonadotrophin-releasing hormone antagonists in the treatment of patients with advanced hormone-dependent prostate cancer in the UK. World J Urol 34(12):1601-1609

38. Tanriverdi F, Gonzalez-Martinez D, Hu Y, Kelestimur F, Bouloux PM (2005) GnRH-I and GnRH-II have differential modulatory effects on human peripheral blood mononuclear cell proliferation and interleukin-2 receptor gamma-chain mRNA expression in healthy males. Clin Exp Immunol 142(1):103-110

39. Chen HF, Jeung EB, Stephenson M, Leung PC (1999) Human peripheral blood mononuclear cells express gonadotropin-releasing hormone $(\mathrm{GnRH}), \mathrm{GnRH}$ receptor, and interleukin-2 receptor gamma-chain messenger ribonucleic acids that are regulated by GnRH in vitro. J Clin Endocrinol Metab 84(2):743-750

40. Bentzon JF, Otsuka F, Virmani R, Falk E (2014) Mechanisms of plaque formation and rupture. Circ Res 114(12):1852-1866

41. Hopmans SN, Duivenvoorden WC, Werstuck GH, Klotz L, Pinthus JH (2014) GnRH antagonist associates with less adiposity and reduced characteristics of metabolic syndrome and atherosclerosis compared with orchiectomy and GnRH agonist in a preclinical mouse model. Urol Oncol 32(8):1126-1134
42. Hupe MC, Hammerer P, Ketz M, Kossack N, Colling C, Merseburger AS (2018) Retrospective analysis of patients with prostate cancer initiating GnRH agonists/antagonists therapy using a German claims database: epidemiological and patient outcomes. Front Oncol 8:543

43. Scailteux LM, Vincendeau S, Balusson F et al (2017) Androgen deprivation therapy and cardiovascular risk: No meaningful difference between GnRH antagonist and agonists-a nationwide population-based cohort study based on 2010-2013 French Health Insurance data. Eur J Cancer 77:99-108

44. Cardwell CR, O'Sullivan JM, Jain S et al (2019) The risk of cardiovascular disease in prostate cancer patients receiving androgen deprivation therapies. Epidemiology 31(3):432-440

45. Perrone V, Degli Esposti L, Giacomini E, Veronesi C, Blini V, Oderda M (2020) Cardiovascular risk profile in prostate cancer patients treated with GnRH agonists versus antagonists: an Italian real-world analysis. Ther Clin Risk Manag 16:393-401

46. Shore ND, Saad F, Cookson MS et al (2020) Oral relugolix for androgen-deprivation therapy in advanced prostate cancer. N Engl J Med 382(23):2187-2196

47. Kirby MG, Allchorne P, Appanna T et al (2019) Prescription switching: rationales and risks. Int J Clin Pract:e13429

48. Miller K, Simson G, Goble S, Persson BE (2015) Efficacy of degarelix in prostate cancer patients following failure on luteinizing hormone-releasing hormone agonist treatment: results from an open-label, multicentre, uncontrolled, phase II trial (CS27). Ther Adv Urol 7(3):105-115

49. Slovin SF, Melloni C, Mansor-Lefebvre S, Neijber A, Roe M (2018) A multicenter, randomized, controlled trial comparing the occurrence of major adverse cardiovascular events (MACEs) in patients (pts) with prostate cancer (pc) and cardiovascular disease (CVD) receiving degarelix (GnRH receptor antagonist) or leuprolide (GnRH receptor agonist). J Clin Oncol 36(15_suppl):TPS5101

Publisher's Note Springer Nature remains neutral with regard to jurisdictional claims in published maps and institutional affiliations. 